\title{
Obesity and Cardiovascular Risk Factors
}

\author{
Maria J Santi-Cano* \\ Research Group on Nutrition: Molecular, pathophysiological and social issues. University of Cádiz, Spain
}

\begin{abstract}
Received: December 03, 2013; Accepted: March 17, 2014; Published: March 20, 2014
*Corresponding author: María J. Santi Cano, Research Group on Nutrition: Molecular, pathophysiological and social issues, University of Cádiz, Avda. Ana de Villa, 52, 11009-Cadiz, Spain, Tel: +34 956 019042; Fax: +34 956 015685; E-mail: mariajose.santi@uca.es
\end{abstract}

\begin{abstract}
Excess bodyweight is an important risk factor for mortality and morbidity from cardiovascular diseases. Obesity and overweight have reached epidemic proportions and it could reverse life-expectancy gains in high-income nations. The aim of this review is to give an update of the present knowledge in cardiovascular consequences of obesity for physicians and other health workers.
\end{abstract}

Methods: In MEDLINE electronic database, a comprehensive search was performed on combinations of both medical subject headings and keywords from 2005 to January 2013. It involved the use of such keywords as overweight, obesity, body weight, combined with the terms prevalence, "cardiovascular risks factors", "cardiovascular disease", atherosclerosis and management. After a brief analysis of the obesity definition, metabolic syndrome and body fat distribution, the cardiovascular complications of obesity will then be reviewed. This will be followed by a discussion on the atherosclerosis pathogenesis in obesity and the management strategies of obesity.

Results: The quality of the manuscripts was assessed and of the 1450 articles identified, 65 studies were selected for this work. The main criteria were: systematic reviews, international consensus guidelines and scientific statements from the major organizations on cardiovascular disease and obesity.

Conclusions: Obesity is becoming a worldwide epidemic in both children and adults. It is directly linked to cardiovascular risk, and it is now considered as a major, independent risk factor for atherosclerosis. Comprehension of the mechanisms leading to obesity, and those linking obesity with cardiovascular disease is crucial for the design of therapeutic strategies targeting atherosclerosis prevention. Accordingly, obesity should be considered as a disease requiring treatment and more importantly prevention in the general population.

Keywords: Obesity; Cardiovascular risk factors

\section{Introduction}

Excess bodyweight is an important risk factor for mortality and morbidity from cardiovascular diseases (CVD), causing early 3 million deaths every year worldwide. Many studies have shown that adiposity, as measured by body mass index [BMI], has increased in recent decades in many populations (Figure 1). Obesity and overweight have reached epidemic proportions and it could reverse life-expectancy gains in high-income nations [14].

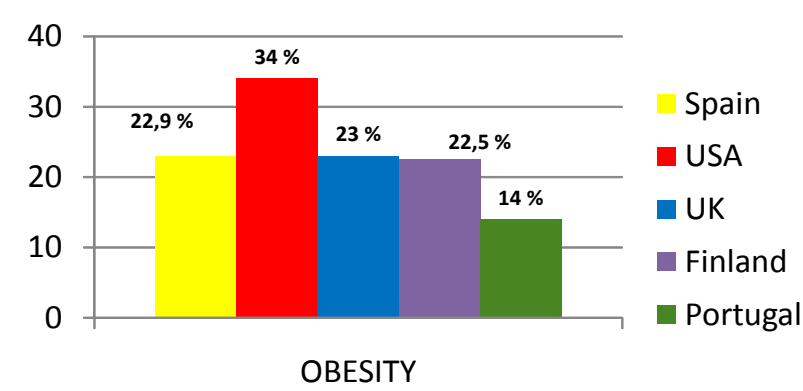

Figure 1: Prevalence of obesity in some countries.

Finucane et al. [5] estimated 1980-2008 trends in mean BMI for 199 countries and they found that mean BMI for men and women increased $0.4 \mathrm{~kg} / \mathrm{m}^{2}$ and $0.5 \mathrm{~kg} / \mathrm{m}^{2}$ per decade respectively [5]. The study showed that in high-income countries, male BMI rose most in the USA ( $1.1 \mathrm{~kg} / \mathrm{m}^{2}$ per decade), followed by the UK $\left(1.0 \mathrm{~kg} / \mathrm{m}^{2}\right.$ per decade), and Australia $\left(0.9 \mathrm{~kg} / \mathrm{m}^{2}\right.$ per decade), and least in, Switzerland, Italy, and France, with increases ranging $0.3-0.4 \mathrm{~kg} / \mathrm{m}^{2}$ per decade.

Moreover, in 2008, male BMI was higher in North America $\left(28.4 \mathrm{~kg} / \mathrm{m}^{2}\right)$ and Australia $\left(27.6 \mathrm{~kg} / \mathrm{m}^{2}\right)$ than in sub-Saharan Africa (apart from southern Africa) and in east, south, and southeast Asia, ranging $20.6-22.9 \mathrm{~kg} / \mathrm{m}^{2}$.

On the other hand, worldwide, prevalence of obesity was $9.8 \%$ in men and $13.8 \%$ in women in 2008 , which were nearly twice the 1980 prevalence of $4.8 \%$ for men and $7.9 \%$ for women. Additionally, the prevalence of obesity in 2008 was highest in North American men, $29.2 \%$ and lowest in South Asia in both men (1.4\%) and women (2.9\%).

In the World Health Organization (WHO) European Region the prevalence of obesity has risen threefold or more since the 1980 s, including countries with traditionally low rates $[6,7]$.

Regarding mortality, Berrington et al. [8] examined the relationship between BMI and all-cause mortality in a pooled analysis of 19 prospective studies, predominantly designed to study cancer, which included 1.46 million white (non-Hispanic) adults and 160,087 deaths [8]. 
They concluded that for non-Hispanic whites, both overweight and obesity were associated with increased all-cause mortality, and all-cause mortality was generally lowest within the BMI range of 20.0 to 24.9 .

Nevertheless, the impact of obesity on life expectancy may be more complex than is commonly recognized. It is possible that the principal impact of obesity is on disability-free life expectancy rather than on life expectancy itself. This has substantial implications for the heath of individuals and the future burden on the health care system [9].

The progression of this epidemic of obesity, in tandem with cardiovascular disease is predicted to slow or reverse the decline in mortality that has been noted in most Western countries over the past $30-40$ years $[10,11]$.

Capewell et al. [12] have reported that in the United States four of the six major risk factors for coronary heart disease (total cholesterol, prevalence of smoking, blood pressure and physical activity levels) improved between 1988 and 2003 [12]. Although, the rate of decline of all-cause and CVD mortality might be faster still if it was not for the increasing prevalence of diabetes, for which there is a clear association with heart disease. Examples of factors driving mortality down include population-wide changes such as reductions in the prevalence and intensity of smoking. However, Stewart et al. have predicted that over the next decade the negative effects of increasing levels of obesity will outweigh the benefits from reductions in the prevalence of smoking [1214].

However, there is the possibility of improved medical interventions in some of the pathways linking obesity to CVD, for example, hypertension and dyslipidemia may blunt the impact of obesity on adverse health outcomes [15].

The aim of this review is to give an update of the present knowledge in cardiovascular consequences of obesity for physicians and other health workers.

\section{Methods}

In MEDLINE electronic database, a comprehensive search was performed on combinations of both medical subject headings and keywords from 2005 to January 2013. It involved the use of such keywords as overweight, obesity, body weight, combined with the terms prevalence, "cardiovascular risks factors", "cardiovascular disease", atherosclerosis and management.

The quality of the manuscripts was assessed and of the 1450 articles identified, 65 studies were selected for this work. The main criteria were: systematic reviews, international consensus guidelines and scientific statements from the major organizations on cardiovascular disease and obesity.

After a brief analysis of the obesity definition, metabolic syndrome and body fat distribution, the cardiovascular complications of obesity will then be reviewed. This will be followed by a discussion on the atherosclerosis pathogenesis in obesity and the management strategies of obesity.

\section{Discussion}

\section{Definition of obesity and metabolic syndrome}

In the most widely used classification of body mass, body weight is expressed in terms of body mass index (BMI). In adults, obesity is defined by a BMI $\geq 30 \mathrm{~kg} / \mathrm{m}^{2}$, which is further subdivided into grades (Table 1) [16].

Obesity has been defined by the American Heart Association as a major modifiable risk factor of cardiovascular disease (CVD). The improvement in risk factor recognition and management that developed through the years in cardiology may be challenged by today's youth who will carry their elevated risk of CVD for many more years [10].

However, obesity is a remarkably heterogeneous condition, where the distribution of the adipose tissue could be more important in determining cardiovascular risk than total body weight.

It appears that obesity as defined solely by BMI cannot always discriminate between the individuals at higher risk of developing CVD. Actually, non-obese overweight patients with excess visceral adiposity, thus at higher risk, would not be detected on the basis of BMI alone. For these reasons, measurement of the waist circumference and a set of metabolic markers have been proposed to detect individuals with the metabolic syndrome (Met S) and higher risk of developing CVD.

\section{Waist circumference}

The optimal level for measurement of waist circumference is midway from the lower rib margin to the anterior superior iliac crest, in the standing position. Thus, the WHO thresholds for waist circumference are the most widely accepted and two action levels are recommended: A) Action level 1, waist circumference $\geq$ $94 \mathrm{~cm}$ in men and $\geq 80 \mathrm{~cm}$ in women represents the threshold at which no further weight should be gained. B) Action level 2, waist circumference $\geq 102 \mathrm{~cm}$ in men and $\geq 88 \mathrm{~cm}$ in women represents the threshold at which weight reduction should be advised [17].

These thresholds have been calculated based on Caucasians and it is apparent that different cut-off points for anthropometric measurements are required in different races and ethnicities (Table 2) [18-26].

Table 1:

\begin{tabular}{|c|c|}
\hline Underweight & BMI $<18.5 \mathrm{~kg} / \mathrm{m}^{2}$ \\
\hline Normal or acceptable weight & BMI $18.5-24.9 \mathrm{~kg} / \mathrm{m}^{2}$ \\
\hline Overweight & BMI $25-29.9 \mathrm{~kg} / \mathrm{m}^{2}$ \\
\hline Obese & $\geq 30 \mathrm{~kg} / \mathrm{m}^{2}$ \\
\hline Grade 1: & BMI $30-34.9 \mathrm{~kg} / \mathrm{m}^{2}$ \\
\hline Grade 2: & BMI $35.0-39.9 \mathrm{~kg} / \mathrm{m}^{2}$ \\
\hline Grade 3: & BMI $\geq 40 \mathrm{~kg} / \mathrm{m}^{2}$ \\
\hline 'Super' obese: & BMI $\geq 50 \mathrm{~kg} / \mathrm{m}^{2}$ \\
\hline
\end{tabular}




\section{Metabolic syndrome}

With respect to the MetS, is often encountered in individuals with obesity and is characterized by a clustering of cardiovascular risk factors including central adiposity, insulin resistence, systemic hypertension, dyslipidemia, pro-inflammatory and prothrombotic state [27].

Various diagnostic criteria have been proposed by different organizations over the past decade. The first formalized definition of the metabolic syndrome was proposed in 1998 by a consultation group on the definition of diabetes for the World Health Organization (WHO) [28]. The other major criteria came from the National Cholesterol Education Program Adult Treatment Panel III (ATP III) in 2001 [29].

In 2005, both the International Diabetes Federation (IDF) and the American Heart Association/National Heart, Lung, and Blood Institute (AHA/NHLBI) attempted to reconcile the different clinical definitions. In spite of this effort, their separate recommendations contained differences related to waist circumference $[18,30]$

Recently, IDF and AHA/NHLBI representatives held discussions to attempt to resolve the remaining differences

Table 2: Current Recommended Waist Circumference Thresholds for Abdominal Obesity by Organization.

\begin{tabular}{|c|c|c|c|}
\hline Population & $\begin{array}{l}\text { Organization } \\
\text { (Reference) }\end{array}$ & Men & Women \\
\hline Europid & IDF (4) & $\geq 94 \mathrm{~cm}$ & $\geq 80 \mathrm{~cm}$ \\
\hline Caucasian & WHO (7) & $\begin{array}{l}\geq 94 \mathrm{~cm} \\
\text { (increased } \\
\text { risk) } \\
\geq 102 \mathrm{~cm} \text { (still } \\
\text { higher risk) }\end{array}$ & $\begin{array}{l}\geq 88 \mathrm{~cm} \\
\text { (increased } \\
\text { risk) } \\
\geq 88 \mathrm{~cm} \text { (still } \\
\text { higher risk) }\end{array}$ \\
\hline United States & $\begin{array}{l}\text { AHA/NHLBI (ATP } \\
\text { III)* (5) }\end{array}$ & $\geq 102 \mathrm{~cm}$ & $\geq 88 \mathrm{~cm}$ \\
\hline Canada & Health Canada $(8,9)$ & $\geq 102 \mathrm{~cm}$ & $\geq 88 \mathrm{~cm}$ \\
\hline European & $\begin{array}{l}\text { European } \\
\text { Cardiovascular } \\
\text { Societies }(10)\end{array}$ & $\geq 102 \mathrm{~cm}$ & $\geq 88 \mathrm{~cm}$ \\
\hline $\begin{array}{l}\text { Asian (including } \\
\text { Japanese) }\end{array}$ & IDF (4) & $\geq 90 \mathrm{~cm}$ & $\geq 80 \mathrm{~cm}$ \\
\hline Asian & WHO (11) & $\geq 90 \mathrm{~cm}$ & $\geq 80 \mathrm{~cm}$ \\
\hline Japanese & $\begin{array}{l}\text { Japanese Obesity } \\
\text { Society (12) }\end{array}$ & $\geq 85 \mathrm{~cm}$ & $\geq 90 \mathrm{~cm}$ \\
\hline China & $\begin{array}{l}\text { Cooperative Task } \\
\text { Force (13) }\end{array}$ & $\geq 85 \mathrm{~cm}$ & $\geq 80 \mathrm{~cm}$ \\
\hline $\begin{array}{l}\text { Middle East, } \\
\text { Mediterranean }\end{array}$ & IDF (4) & $\geq 94 \mathrm{~cm}$ & $\geq 80 \mathrm{~cm}$ \\
\hline $\begin{array}{l}\text { Sub-Saharan } \\
\text { African }\end{array}$ & IDF (4) & $\geq 94 \mathrm{~cm}$ & $\geq 80 \mathrm{~cm}$ \\
\hline $\begin{array}{l}\text { Ethnic Central and } \\
\text { South American }\end{array}$ & IDF (4) & $\geq 90 \mathrm{~cm}$ & $\geq 80 \mathrm{~cm}$ \\
\hline
\end{tabular}

*Recent AHA/NHLBI guidelines for metabolic syndrome recognize an increased risk for CVD and diabetes at waist-circumference thresholds of $\geq 94 \mathrm{~cm}$ in men and $\geq 80 \mathrm{~cm}$ in women and identify these as optional cut points for individuals or populations with increased insulin resistance. between definitions of metabolic syndrome. Both sides agreed that abdominal obesity should not be a prerequisite for diagnosis but that it is 1 of 5 criteria, so that the presence of any 3 of 5 risk factors constitutes a diagnosis of metabolic syndrome. This would result in the common definition shown in Table 3. Table 2 shows current international recommendations proposed for thresholds of abdominal obesity to be used as one component of the metabolic syndrome [27]. Table 2 also lists waist circumference thresholds currently being recommended in several different populations and ethnic groups. Although some uncertainty about the Met $\mathrm{S}$ exists, it remains useful in identifying CVD risk.

\section{Body fat distribution: Metabolically healthy obesity and non-obese individuals at increased risk for CVD.}

Although it is well recognized that obesity is a health hazard, its heterogeneity has remained a challenge in clinical practice [31]. For instance, whereas there is a clear link between obesity and complications such as dyslipidemia, hypertension, and type 2 diabetes, not every obese patient is characterized by these risk factors.

Hamer et al. [32] have provided evidence that one can find individuals with a diagnosis of clinical obesity defined on the basis of their BMI but without the expected cardiovascular disease risk factors. The proportion of obese individuals who were nevertheless metabolically healthy represented about $22 \%$ of the sample of obese participants examined in this cohort. Thus, we need to identify them in clinical practice because they do not share the risk burden of their peers. On the other hand, there was also a subgroup of non-obese individuals who were characterized by metabolic risk factors (about $25 \%$ of participants with a BMI $<30 \mathrm{~kg} / \mathrm{m}^{2}$ ) and who were at increased risk for CVD and total mortality. Thus, the BMI don't seems to be the optimal anthropometric variable to estimate the health hazards of obesity [32].

There is now emerging evidence from several computed tomography and magnetic resonance imaging studies that excess visceral adiposity and liver fat content are two key drivers of cardio metabolic risk associated with a given level of total body fat. It is therefore very likely that obese individuals who are metabolically healthy have low levels of visceral adipose tissue and of liver fat, whereas non-obese metabolically unhealthy individuals probably have increased levels of visceral fat. Crosssectional analyses of large metabolic/imaging studies have revealed considerable individual variation in visceral adiposity fat at any BMI level [33-36].

Nevertheless, adiposity indices are powerful correlates of deteriorated levels of intermediate risk factors. These strong associations between body fatness variables and risk factors are not trivial and have important public health implications. Therefore, we should help patients to lose weight and improve their lifestyle habits [37].

One simple clinical approach that has been proposed to identify the subgroup of individuals with an excess of visceral adipose tissue is the simultaneous measurement and interpretation 
Table 3: Criteria for Clinical Diagnosis of the Metabolic Syndrome.

\begin{tabular}{|c|c|}
\hline Measure & Categorical cut points \\
\hline Elevated waist circumference* & $\begin{array}{c}\text { Population- and } \\
\text { country-specific definitions }\end{array}$ \\
\hline $\begin{array}{l}\text { Elevated triglycerides (drug } \\
\text { treatment } \\
\text { for elevated triglycerides is an } \\
\text { alternate indicator } \dagger \text { ) }\end{array}$ & $\geq 150 \mathrm{mg} / \mathrm{dL}(1.7 \mathrm{mmol} / \mathrm{L})$ \\
\hline $\begin{array}{l}\text { Reduced HDL-C (drug treatment for } \\
\text { reduced HDL-C is an alternate } \\
\text { indicator } \dagger \text { ) }\end{array}$ & $\begin{array}{c}\leq 40 \mathrm{mg} / \mathrm{dL}(1.0 \mathrm{mmol} / \mathrm{L}) \text { in } \\
\text { males; } \leq 50 \mathrm{mg} / \mathrm{dL}(1.3 \mathrm{mmol} / \mathrm{L}) \\
\text { in } \\
\text { Females }\end{array}$ \\
\hline $\begin{array}{c}\text { Elevated blood pressure } \\
\text { (antihypertensive drug treatment } \\
\text { in a } \\
\text { patient with a history of } \\
\text { hypertension } \\
\text { is an alternate indicator) }\end{array}$ & $\begin{aligned} \text { Systolic } & \geq 130 \text { and/or diastolic } \\
& \geq 85 \mathrm{~mm} \mathrm{Hg}\end{aligned}$ \\
\hline $\begin{array}{l}\text { Elevated fasting glucose } \neq \text { (drug } \\
\text { treatment of elevated glucose is an } \\
\text { alternate indicator) }\end{array}$ & $\geq 100 \mathrm{mg} / \mathrm{dL}$ \\
\hline
\end{tabular}

HDL-C indicates high-density lipoprotein cholesterol.

*It is recommended that the IDF cut points be used for non-Europeans and either the IDF or AHA/NHLBI cut points used for people of European origin until more data are available.

†The most commonly used drugs for elevated triglycerides and reduced HDL-C are fibrates and nicotinic acid. A patient taking 1 of these drugs can be presumed to have high triglycerides and low HDL-C. High-dose $\Omega-3$ fatty acids presumes high triglycerides.

$\ddagger$ Most patients with type 2 diabetes mellitus will have the metabolic syndrome by the proposed criteria.

of elevated waist circumference and plasma triglyceride concentrations, a phenotype referred to as "hypertriglyceridemic waist". It is suggested that hypertriglyceridemic waist could have been helpful to identify non-obese metabolically unhealthy individuals with an excess of visceral adipose tissue [38]. Many studies have shown that this simple phenotype could discriminate a large proportion of individuals with excess visceral fat and that this condition was also predictive of an increased CVD risk [3941].

Finally, another powerful modulator of CVD risk associated with a given BMI is the level of physical activity and fitness. Although cardio respiratory fitness has a genetic component, it is also a marker of participation to vigorous physical activities [14]. Blair et al. have shown that the so-called "fat and fit" individuals are at substantially reduced risk for clinical outcomes such as type 2 diabetes and CVD despite their high level of adiposity [42].

Indeed, these studies have demonstrated that a high level of cardio respiratory fitness is even more important as a cardio protective factor than low adiposity. In this regard, some authors, have reported that fat and fit individuals were also characterized by low levels of visceral adipose tissue and of inflammatory markers $[43,44]$. Thus, metabolically healthy obese subjects probably have less visceral adipose tissue fat and may be more fit, and these two factors could largely explain the absence of increased CVD risk despite their clinical obesity defined on the basis of the BMI.
Thus, obesity assessed only by the BMI cannot properly estimate CVD and all-cause mortality risk. Furthermore, the therapeutic objective of achieving a normal BMI to prevent cardio metabolic diseases may also be questioned on the basis of the emerging evidence. In this regard, it have been recently proposed that increased participation in vigorous physical activity to reduce visceral adiposity fat and to maintain a proper level of insulin sensitivity may be more important than achieving a "healthy" body weight defined by the BMI. Therefore, evidence support that obesity should be assessed using waist circumference as measure of visceral fat.

\section{Cardiovascular complications of obesity}

Obesity and cardiovascular disease.

Obesity and stroke: Numerous studies have reported an association between BMI and stroke. Indeed obesity is considered as a potential modifiable risk factor for stroke and the independence of this relationship from cholesterol, systemic hypertension and diabetes was identified. Each 1-Unit increase in BMI was associated with a increase of $4 \%$ in the risk of ischemic stroke and 6\% for hemorrhagic stroke. However, stroke severity for ischemic stroke was not associated with BMI. The increase of stroke in obesity may be predicted by the pro-thrombotic and pro-inflammatory state that so often accompanies excessive adipose tissue accumulation [45].

Coronary heart disease (CHD): In adults, it has been shown that visceral obesity is associated with maximal density of macrophages in atherosclerotic lesions, reduced coronary flow reserve and insulin resistance and MetS is associated with lipidrich plaque. However, obesity was associated, with lower allcause and cardiovascular mortality after unstable angina or nonST-segment elevation myocardial infarction treated with early revascularization. This has been described in the literature as the 'obesity paradox' and it may reflect the lack of discriminatory power of BMI to adequately reflect body fat distribution [46, 47].

Congestive heart failure: Elevated BMI predisposes to congestive heart failure [CHF] by promoting hypertension, diabetes, and CHD. It is estimated that there is an increase in the risk of $\mathrm{CHF}$ of $5 \%$ for men and $7 \%$ for women for each increment of 1 Unit of BMI. In contrast, once the patient presents with CHF, the presence of obesity may not adversely affect the patient's outcome. Indeed, among patients with CHF, subjects with higher BMI are at decreased risk for death and hospitalization ("obesity paradox") compared with patients with a normal BMI $[45,48]$.

Hypertension: The majority of patients with high blood pressure are overweight, and hypertension is more frequent in obese subjects. A $10 \mathrm{~kg}$ higher body weight is associated with a $3.0 \mathrm{~mm}$ higher systolic and $2.3 \mathrm{~mm} \mathrm{Hg}$ higher diastolic blood pressure. These increases translate into an estimated $12 \%$ increased risk for CHD and $24 \%$ increased risk for stroke. This increase in blood pressure is greatest when the obesity is of abdominal distribution $[45,49]$.

Arrythmias: Obese subjects have an increased risk of arrhythmias and sudden death, even in the absence of cardiac 
dysfunction, and the risk of sudden cardiac death with increasing weight is seen in both genders. In the Framingham study, the annual sudden cardiac mortality rate in obese men and women was estimated to be approximately 40 times higher than the rate of unexplained cardiac arrest in a matched non-obese population. Prolonged QTc interval was observed in approximately $30 \%$ of subjects with impaired glucose tolerance, and there is a positive association between BMI and QTc [45, 50].

The relationship between obesity and cardiovascular disease is associated with atherosclerosis and altered cardiac function by different mechanisms as insulin resistance, diabetes mellitus, adipokines, dyslipidemia, ventricle hypertrophy, fatty heart and endothelium dysfunction.

\section{Atherosclerosis pathogenesis and altered cardiac function in obesity}

The relation between obesity and CVD is indeed complicated Some investigators suggest that the connection is indirect and dependent on the increased prevalence of diabetes, hypertension and dyslipidemia, whereas others have demonstrated an independent association between obesity (especially abdominal obesity) and CVD risk. The relationship between obesity and CVD appears to develop at a relatively young age and is associated with atherosclerosis [51].

Obesity and insulin resistance: Obesity leads to insulin resistance via various, frequently inter-related, mechanisms. Infiltration of fat into the pancreatic islet cells amplifies the agerelated decline in the islets' capacity to maintain the increased insulin output demanded by insulin resistance, and so glucose intolerance and premature type 2 diabetes mellitus readily develop [52].

Furthermore adipose tissue-derived products or adipokines are believed to be actively involved in the regulation of insulin sensitivity in peripheral tissues. Obesity-related modifications in adipocytes function induce a paracrine suppressive effect on adiponectin expression, a powerful insulin sensitizer, down regulated in obesity. In addition up regulation of proinflammatory adipokines in obesity like interleukin (IL)-1,6 and tumor necrosis factor-alpha (TNF- $\alpha$ ), also contributes to blunted insulin-signaling in peripheral tissues.

Obese individuals have decreased insulin receptor expression and decreased tyrosine kinase activity in skeletal muscle cells and adipocytes. Both insulin receptor expression and its tyrosine kinase activities are restored by weight loss, which also improves insulin sensitivity [54].

In abdominal obesity, omental and mesenteric adipose depots liberate high concentrations of non-esterified fatty acids (NEFA) directly into the portal vein with direct negative effects on liver metabolism of glucose. NEFA also directly stimulate insulin secretion by pancreatic $\beta$-cells, while they compete with glucose use by skeletal muscles as energy substrate, further aggravating insulin resistance [55].

Obese individuals have insulin resistance in adipose tissue (light resistance), liver (light resistancer) and skeletal muscles (severe resistance). Indeed, while in lean subjects, glucose uptake occurs primarily in skeletal muscles, in obese occurs in adipocytes and that increase obesity. The transfer of nutrients to adipose tissue may cause hypertrophy and hyperplasia of fat tissue.

Obesity and diabetes mellitus: Most of type 2 diabetic patients are overweight supporting the hypothesis that excess adipose tissue mass may play an important role in the pathogenesis of the disease. Around $90 \%$ of individuals who develop type 2 diabetes mellitus have BMI higher than $23.0 \mathrm{~kg} /$ $\mathrm{m}^{2}$. First, it develops glucose intolerance and if obesity persists, type 2 diabetes mellitus .

An increase in type 2 diabetes may have significant impact on public health and could reverse in the future, the trend toward decreasing CVD mortality [54].

Obesity and adipose tissue function: Initially, adipose tissue was believed to be a passive depot for storing excess calories. More recently, however, studies have revealed that visceral adipose tissue is metabolically active organ capable of synthesizing and releasing into the bloodstream an important variety of peptides and non-peptide compounds molecules implicated in cardiovascular pathophysiology.

These mediators or adipokines are actively implicated in the atherosclerotic process and include adiponectin, resistin, leptin, plasminogen activator inhibitor-1 (PAI-1), TNF- $\alpha$, IL- 6 and other less well-characterized molecules [56, 57].

Expression of some adipokines is elevated in obese and a reduction in fat mass is strongly correlated with a decrease in circulating proinflammatory adipokines levels. Indeed visceral fat depot seems to be more active than other body fat depots in producing a variety of these adipokines.

Among these mediators, leptin is an adipokine implicated in the regulation of appetite and increases blood pressure, sympathetic nerve activity, reactive oxygen species, platelet aggregation and arterial thrombosis. Clinical studies show that leptin is increased in obesity and is an independent CHD risk factor and a potentially useful biomarker in CVD.

Adiponectin, has insulin sensitizing properties and is down regulated in obesity. Firm evidence suggests that adiponectin has many anti-inflammatory and anti-atherogenic effects both on myocardium and vascular wall. Interestingly adiponectin plasma levels have been found to be more closely related to the amount of visceral than total fat.

On the other hand TNF- $\alpha$, interleukina- 6 and PAI-1 levels are up regulated in obesity and associated with visceral fat. Conclusively altered expression of adipokines in obesity might be partly responsible for the insulin resistance state and accelerated atherosclerosis in obese individuals [51].

Obesity and dyslipidemia: Obesity is characterized by impaired adipocytes trapping of fatty acids and excessive adipocytes lipolysis. These alterations lead to high circulating NEFA levels that result in increased hepatic lipogenesis. 
Overwhelming of hepatic secretory capacity leads to hepatic steatosis by the newly synthesized triglycerides (TG) and increased VLDL circulating levels. An impaired lipoprotein lipase activity and enhanced cholesteryl ester transfer protein (CETP)mediated lipid exchanged contribute to the observed HDL-C reduction in obesity.

Atherogenic dyslipidemia is clinically presented as elevated serum TG levels, increased levels of small dense low-density lipoprotein particles, and decreased levels of HDL-C. The use of WC $\geq 90 \mathrm{~cm}$ for men in combination with plasma TG levels $\geq 2 \mathrm{mmol} / \mathrm{L}$ has shown to be highly discriminatory for the development of CHD [51,58]. .

Ventricle hypertrophy and fatty heart in obesity: It has been long known that morbidly obese subjects develop obesityrelated cardiomyopathy. Compared with subjects with a normal BMI, obese subjects had a doubling of heart failure (HF) risk. However it should be also noted that in HF patients higher BMI is not an adverse prognostic feature. Instead patients with low BMI seem to have poorer prognosis, a fact possibly dependent on HFrelated cachexia ("obesity paradox").

Ample evidence suggests that obesity is associated with altered cardiac hemodynamics. Obesity is characterized by a hyperdynamic circulation in order to maintain metabolic demands in the excess adipose depots. Furthermore obesityrelated hypertension imposes an elevated afterload to left ventricle, while obstructive sleep apnea disorders may also augment right ventricular afterload. This altered hemodynamic profile may lead to eccentric or even concentric left ventricle hypertrophy with impaired diastolic function parameters.

Probably the fatty heart is a metaplastic phenomenon. Cords of fat cells can gradually accumulate fat between muscle fibers or cause myocyte degeneration resulting in cardiac conduction defects. These cords of fat cells may also emanate from epicardial fat. Particularly interesting are the possible effects of epicardial fat on myocardium. Epicardial fat constitutes a visceral adipose depot and is a significant source of proinflammatory mediators, thus, clinical and imaging studies have demonstrated a strong correlation between epicardial fat mass and visceral adiposity $[51,59]$.

Obesity, endothelium dysfunction and atherosclerosis: It is well established that higher BMI is associated with subclinical inflammation, reflected in increased C-reactive protein levels, and increased systemic oxidative stress. Evidence suggests that both insulin resistance and hyperinsulinemia lead to endothelial dysfunction. In insulin resistant individuals, insulin-mediated nitric oxide (NO) release is impaired and prostacyclin levels and potassium-mediated vasodilatation are reduced. Therefore an imbalance between vasodilatory and vasoconstrictive agents is favoured, and NO beneficial anti-inflammatory, antioxidant and antithrombotic effects are lost.

Proinflammatory cytokines increase expression of adhesion molecules on endothelial cells surface like intercellular adhesion molecule-1 and vascular cell adhesion molecule-1 (VCAM-1) which promote monocytes infiltration into subendothelial space.

Furthermore, $\mathrm{T}$ lymphocytes are also activated and further enhance macrophage atherogenic ability. Additionally, insulin has proliferative effects on vascular smooth muscle cells and insulin and promote extracellular matrix degradation and atheromatous plaque rupture.

Altered adipokines expression by adipose tissue is an additional factor responsible for perpetuating the vicious cycle of inflammation and endothelial dysfunction. Recent evidence suggests that leptin stimulates cholesterol uptake by macrophages, particularly in the presence of high glucose, triggering the formation of foam cells and the development of atheromatic lesions. Obesity-related hypoadiponectinemia might also contribute to impaired endothelial function, increased vascular reactive oxygen species (ROS) production and overall proatherogenic effects. Finally increased release of proinflammatory cytokines by adipose tissue, like IL-6, IL-1 and TNF- $\alpha$, sustains vascular wall inflammation and promotes proatherogenic genes expression [51,60,61].

\section{Management strategies of obesity}

It is now well understood that obesity, in particular abdominal adiposity, is associated with increased risk of CVD and diabetes mellitus. Obesity is one of the nine easily evaluated, modifiable risk factors (abnormal lipids, smoking, hypertension, diabetes, abdominal obesity, consumption of fruits, vegetables, alcohol and physical activity), that account for more than $90 \%$ of AMI risk.

Evidence suggests that routine measurement of waist circumference in addition to BMI is a useful clinical marker for CVD risk assessment even in patients with normal weight [62].

Management strategies of major risk factors should be number one priority in obese patients (Table 4).

"Healthy" lifestyle modifications, like discontinuing smoking, decreasing fat and cholesterol content in diet, consuming vegetables and fruits and exercising regularly (at least $30 \mathrm{~min}$ of moderate activity a day) should also be encouraged. In cases of severe obesity drugs for weight loss or even surgical treatment of obesity can be tested. Nevertheless it should be noted that both drugs and surgery are often associated with adverse side-effects and complications $[63,64]$.The target behaviors for obesity prevention are summarized in Table 5 [65].

Limitations of the study. This study has several limitations.

Table 4: Recommended strategies of major risks factors.

\begin{tabular}{|l|l|}
\hline WC & $<102 \mathrm{~cm}$ (men) / $<88 \mathrm{~cm}$ (women). \\
\hline Blood pressure: & $\begin{array}{l}<140 / 90 \mathrm{mmHg} \text { (or }<130 / 80 \mathrm{mmHg} \text { for patients } \\
\text { with diabetes mellitus or chronic kidney disease). }\end{array}$ \\
\hline $\begin{array}{l}\text { Ratio of total } \\
\text { cholesterol/ } \\
\text { HDL-C: }\end{array}$ & $<6$. \\
\hline $\begin{array}{l}\text { Fasting plasma } \\
\text { glucose: }\end{array}$ & $<110 \mathrm{mg} / \mathrm{dL}(6 \mathrm{mmol} / \mathrm{L})$ \\
\hline HbA1c: & $<6.5 \%$. \\
\hline
\end{tabular}


Table 5: Behavior Targets for Obesity Prevention.

\begin{tabular}{|c|c|c|}
\hline Diet & Activity & others \\
\hline $\begin{array}{l}\text { To increase consumption of fruits, vegetables, } \\
\text { legumes, whole grains and nuts. } \\
\text { Limit calories from added sugars, solid fats, } \\
\text { fruits and alcohol. } \\
\text { To decrease consumption of sugar-sweetened } \\
\text { beverages/soft drinks. } \\
\text { To promote breastfeeding initiation, duration, } \\
\text { and exclusivity. } \\
\text { To decrease consumption of high-calorie, } \\
\text { energy-dense foods. } \\
\text { Accept ability to regulate energy intake rather } \\
\text { than eating until the plate is empty. } \\
\text { Ensure appropriate micronutrient intake to } \\
\text { promote optimal linear growth. }\end{array}$ & $\begin{array}{l}\text { To increase physical activity and promote an } \\
\text { active lifestyle. } \\
\text { Children: } \geq 60 \text { min of physical activity per day. } \\
\text { Adults: } \geq 150 \text { min of moderate-intensity or } 75 \\
\text { min of vigorous-intensity physical activity per } \\
\text { week. } \\
\text { To decrease television viewing. }\end{array}$ & $\begin{array}{l}\text { Limit exposure of young children to heavy } \\
\text { marketing of energy-dense, micronutrient-poor } \\
\text { foods. } \\
\text { Provide information and skills necessary to } \\
\text { make healthy food choices. }\end{array}$ \\
\hline
\end{tabular}

First, the obesity definition was based on BMI and waist circumference. Anthropometric measurements are useful indices in clinical practice, however they do not distinguish abdominal (visceral) fat from subcutaneous abdominal fat. Therefore more sophisticated methods for assessing body fat compartments could be useful, like magnetic resonance imaging, computerized tomography, or even ultrasound. They could add valuable information on cardiovascular risk stratification. Second, this review states BMI and waist circumference thresholds in different populations but obviously, there are many people in the world of mixed ethnicity. With respect to this, additional studies are needed. Finally, another powerful modulator of CVD risk associated with a given BMI is the level of physical activity/ fitness and it was not included in this review.

\section{Conclusions}

Obesity is becoming a worldwide epidemic in both children and adults. It is directly linked to cardiovascular risk, and it is now considered as a major, independent risk factor for atherosclerosis. Comprehension of the mechanisms leading to obesity, and those linking obesity with cardiovascular disease is crucial for the design of therapeutic strategies targeting atherosclerosis prevention. Accordingly, obesity should be considered as a disease requiring treatment and more importantly prevention in the general population.

\section{References}

1. Whitlock G, Lewington S, Sherliker P, Clarke R, Emberson J, et al. (2009) Body-mass index and cause-specific mortality in 900000 adults: collaborative analyses of 57 prospective studies. Lancet 373(9669): 1083-1096.

2. Poirier P, Giles TD, Bray GA, Hong Y, Stern JS, et al. (2006) Obesity, Cardiovascular Disease: Pathophysiology, Evaluation, Effect Of Weight Loss: An Update Of The 1997 American Heart Association Scientific Statement On Obesity And Heart Disease From The Obesity Committee Of The Council On Nutrition, Physical Activity, And Metabolism. Circulation 113: 898-918.

3. Stewart ST, Cutler DM, Rosen AB (2009) Forecasting the effects of obesity and smoking on U.S. life expectancy. N Engl J Med 361(23): 2252-2260.
4. Pischon T, Boeing H, Hoffmann K, Bergmann M, Schulze MB, et al. (2008) General and abdominal adiposity and risk of death in Europe. N Engl J Med 359(20): 2105-2120.

5. Finucane MM, Stevens GA, Cowan MJ, Danaei G, Lin JK, et al. (2011) National, regional, and global trends in body-mass index since 1980: systematic analysis of health examination surveys and epidemiological studies with 960 country-years and $9 \cdot 1$ million participants. Lancet 377(9765): 557-567.

6. Branca F, Nikogosian H, Lobstein T (2007) The Challenge of Obesity in the WHO European Region and the Strategies for Response. WHO Regional Office for Europe: Copenhagen, Denmark.

7. Doak CM, Wijnhoven TM, Schokker DF, Visscher TL, Seidell JC (2012) Age standardization in mapping adult overweight and obesity trends in the WHO European Region. Obes Rev 13(2): 174-191.

8. Berrington de Gonzalez A, Hartge P, Cerhan JR, Flint AJ, Hannan L, et al. (2010) Body-Mass Index and Mortality among 1.46 Million White Adults. N Engl J Med 363:2211-2219.

9. Helen L Walls, Kathryn Backholer, Joseph Proietto, John J McNeil (2012) Obesity and Trends in Life Expectancy. Journal of Obesity: 1-4.

10. Olshansky SJ, Passaro DJ, Hershowet RC, Layden J, Carnes BA, et al. (2005) A potential decline in life expectancy in the United States in the 21st century. N Engl J Med 352(11): 1138-1145.

11. Parikh NI, Pencina MJ, Wang TJ, Lanier KJ, Fox CS, et al. (2007) Increasing Trends in Incidence of Overweight and Obesity over 5 Decades. Am J Med 120(3): 242-250.

12. Capewell S, Ford ES, Croft JB, Critchley JA, Greenlund KJ, et al. (2010) Cardiovascular risk factor trends and potential for reducing coronary heart disease mortality in the United States of America. Bulletin of the World Health Organization 88(2): 120-130.

13. Fox CS, Pencina MJ, Meigs JB, Vasan RS, Levitzky YS, et al. (2006) Trends in the incidence of type 2 diabetes mellitus from the 1970s to the 1990s: the Framingham Heart Study. Circulation 113(25): 29142918.

14. Stewart ST, Cutler DM, Rosen AB (2009) Forecasting the effects of obesity and smoking on U.S. life expectancy. N Engl J Med 361(23): 2252-2260.

15. Chobanian AV (2010) Improved hypertension control: cause for some celebration .JAMA 303(20): 2082-2083.

16. Poirier P, Eckel RH (2008) Cardiovascular consequences of Obesity 
Drug Discovery Today 5(1): 45-51.

17. World Health Organization (WHO) (1998) Obesity: Preventing and Managing the Global Epidemic. Report of a WHO Consultation. World Health Organ Tech Rep Ser 894: 1-253.

18. Grundy SM, Cleeman JI, Daniels SR, Donato KA, Eckel RH, et al. (2005) Diagnosis and management of the metabolic syndrome: an American Heart Association/National Heart, Lung, and Blood Institute Scientific Statement. Circulation 112(17): 2735-2752.

19. World Health Organization (WHO) (2000) Obesity: Preventing and Managing the Global Epidemic: Report on a WHO Consultation World Health Organization technical Report Series 894, Geneva, Switzerland.

20. National Institutes Of Health (1998) Clinical Guidelines On The Identification, Evaluation, And Treatment Of Overweight And Obesity In Adults-- The Evidence Report. Obes Res. 6(2): 51S-209S.

21. Health Canada (2003) Canadian Guidelines for Body Weight Classification in Adults. Canada: Health Canada Publications Centre, Ottawa.

22. Khan NA, McAlister FA, Rabkin SW, Padwal R, Feldman RD, et al. (2006) The 2006 Canadian Hypertension Education Program recommendations for the management of hypertension, part IItherapy. Can J Cardiol 22(7): 583-593.

23. Graham I, Atar D, Borch-Johnsen K, Boysen G, Burell G, et al. (2007) ESC Committee for Practice Guidelines. European guidelines on cardiovascular disease prevention in clinical practice: executive summary. Atherosclerosis 194(1): 1- 45.

24. Hara K, Matsushita Y, Horikoshi M, Yoshiike N, Yokoyama T, et al.(2006) A proposal for the cutoff point of waist circumference for the diagnosis of metabolic syndrome in the Japanese population. Diabetes Care 29:1123-1124.

25. Oka R, Kobayashi J, Yagi K, Tanii H, Miyamato S, et al. (2008) Reassessment of the cutoff values of waist circumference and visceral fat for identifying Japanese subjects at risk for the metabolic syndrome. Diabetes Res Clin Pract 79(3): 474-481.

26. New criteria for "obesity disease" in Japan ( 2002) Examination Committee of Criteria for "Obesity Disease" in Japan; Japan Society for the Study of Obesity. Circ J 66(11): 987-992.

27. Alberti KG, Eckel RH, Grundy SM, Zimmet PZ, Cleeman JI, et al. (2009) Harmonizing the Metabolic Syndrome: a Joint Interim Statement of the International Diabetes Federation Task Force on Epidemiology and Prevention National Heart, Lung, and Blood Institute American Heart Association World Heart Federation International Atherosclerosis Society and International Association for the Study of Obesity. Circulation 120(16): 1640-1645.

28. Alberti KG, Zimmet PZ (1998) Definition, diagnosis and classification of diabetes mellitus and its complications. Part 1: diagnosis and classification of diabetes mellitus provisional report of a WHO consultation. Diabet Med 15(7): 539-553.

29. National Cholesterol Education Program (NCEP) (2002) Third Report of the National Cholesterol Education Program (NCEP) Expert Panel on Detection, Evaluation, and Treatment of High Blood Cholesterol in Adults (Adult Treatment Panel III) final report. Circulation 106(25): 3143-3421.

30. Alberti KG, Zimmet P, Shaw J (2005) The metabolic syndrome: a new worldwide definition. Lancet 366(9491): 1059 -1062.

31. Despre's JP, Lemieux I (2006) Abdominal obesity and metabolic syndrome. Nature 444(7121): 881-887.
32. Hamer M (2012) Metabolically healthy obesity and risk of all-cause and cardiovascular disease mortality. J Clin Endocrinol Metab 97(7): 2482-2488.

33. Kotronen A, Westerbacka J, Bergholm R, Pietiläinen KH, Yki-Järvinen $\mathrm{H}$, et al. (2007) Liver fat in the metabolic syndrome. J Clin Endocrinol Metab 92(9): 3490-3497.

34. Sam S, Haffner S, Davidson MH, D’ Agostino RB Sr, Feinstein S, et al (2008) Relationship of abdominal visceral and subcutaneous adipose tissue with lipoprotein particle number and size in type 2 diabetes. Diabetes 57(8): 2022-2027.

35. Ross R, Aru J, Freeman J, Hudson R, Janssen I, et al. (2002) Abdominal adiposity and insulin resistance in obese men. Am J Physiol Endocrinol Metab 282(3): E657-E663.

36. Després JP1, Moorjani S, Ferland M, Tremblay A, Lupien PJ, et al. (1989) Adipose tissue distribution and plasma lipoprotein levels in obese women. Importance of intra-abdominal fat. Arteriosclerosis 9(2): 203-210.

37. Wormser D, Kaptoge S, Di Angelantonio E, Wood AM, Pennells L, et al. (2011) Separate and combined associations of body-mass index and abdominal adiposity with cardiovascular disease: collaborative analysis of 58 prospective studies. Lancet 377(9771): 1085-1095.

38. Lemieux I, Pascot A, Couillard C, Lamarche B, Tchernof A, et al. (2000) Hypertriglyceridemic waist: A marker of the atherogenic metabolic triad (hyperinsulinemia; hyperapolipoprotein B; small, dense LDL) in men? Circulation 102(2): 179-184.

39. Lemieux I, Poirier P, Bergeron J, Alme'ras N, Lamarche B, et al. (2007) Hypertriglyceridemic waist: a useful screening phenotype in preventive cardiology? Can J Cardiol 23: 23B-31B.

40. Arsenault BJ, Lemieux I, Despre's JP, Wareham NJ, Kastelein JJ, et al.(2010) The hypertriglyceridemic-waist phenotype and the risk of coronary artery disease: results from the EPIC-Norfolk prospective population study. CMAJ 182(13): 1427-1432.

41. Santi MJ, Carrozas, MA, Barba A, Astola A, Jiménez A, et al. (2005) Mangas A. Waist circumference as a predictor of insulin resistance in young men. Med Clin (Barc) 125(2): 46-50.

42. Lee DC, Sui X, Church TS, Lee IM, Blair SN. (2009) Associations of cardio respiratory fitness and obesity with risks of impaired fasting glucose and type 2 diabetes in men. Diabetes Care 32(2): 257-262.

43. Arsenault BJ, Lachance D, Lemieux I, Alméras N, Tremblay A, et al.(2007) Visceral adipose tissue accumulation, cardiorespiratory fitness, and features of the metabolic syndrome. Arch Intern Med 167(14): 1518-1525.

44. Arsenault BJ, Cartier A, Côté M, Lemieux I, Tremblay A, et al.(2009) Body composition, cardiorespiratory fitness, and low-grade inflammation in middle-aged men and women. Am J Cardiol 104(2): 240-246.

45. Poirier P, Giles TD, Bray GA, Hong Y, Stern JS, et al. (2006) Obesity and Cardiovascular Disease: pathophysiology, evaluation, and effect of weight loss. Arterioscler Thromb Vasc Biol 26(5):968-976.

46. Amano T, Matsubara T, Uetani T, Nanki M, Marui N, et al. (2007) Impact of metabolic syndrome on tissue characteristics of angiographically mild to moderate coronary lesions. J Am Coll Cardiol 49(11): 11491156.

47. Romero-Corral A, Montori VM, Somers VK, Korinek J, Thomas RJ, et al. (2006) Association of bodyweight with total mortality and with cardiovascular events in coronary artery disease: a systematic review 
of cohort studies. Lancet 368(9536): 666-678.

48. Kenchaiah S, Evans JC, Levy D, Wilson PW, Benjamin EJ, et al. (2002) Obesity and the risk of heart failure. N Engl J Med 347(5): 305-313.

49. Poirier P, Lemieux I, Mauriège P, Dewailly E, Blanchet C, et al. (2005) Impact of waist circumference on the relationship between blood pressure and insulin: the Quebec Health Survey. Hypertension 45(3):363-367

50. Brown DW, Giles WH, Greenlund KJ, Valdez R, Croft JB (2001) Impaired fasting glucose, diabetes mellitus, and cardiovascular disease risk factors are associated with prolonged QTc duration. Results from the Third National Health and Nutrition Examination Survey. J Cardiovasc Risk 8(4):227-233

51. Marinou K, Tousoulis D, Antonopoulos AS, Stefanadi E, Stefanadis C (2010) Obesity and cardiovascular disease: from pathophysiology to risk stratification. Int J Cardiol 138(1): 3-8.

52. Assimacopoulos-Jeannet F (2004) Fat storage in pancreas and in insulin-sensitive tissues in pathogenesis of type 2 diabetes. Int J Obes Relat Metab Disord 28(4): S53-S57.

53. Ryo M, Nakamura T, Kihara S, Kumada M, Shibazaki S et al. (2004) Adiponectin as a biomarker of the metabolic syndrome. Circ J 68(11): 975-981.

54. Abate N (2000) Obesity and cardiovascular disease. Pathogenetic role of the metabolic syndrome and therapeutic implications. J Diabetes Complications 14(3): 154-74.

55. Frayn KN (2000) Visceral fat and insulin resistance--causative or correlative? Br J Nutr 83(1): S71-77.

56. Tousoulis D, Antoniades C, Stefanadis C (2007) Assessing inflammatory status in cardiovascular disease. Heart 93(8): 1001-1007.
57. Amasyali B, Kose S, Kursaklioglu H, Kilic A, Isik E (2008) Leptin in acute coronary syndromes: Has the time come for its use in risk stratification? Int J Cardiol 130(2): 264-265.

58. Bamba V, Rader DJ (2007) Obesity and atherogenic dyslipidemia. Gastroenterology 132(6): 2181-2190.

59. Rabkin SW (2007) Epicardial fat: properties, function and relationship to obesity. Obes Rev 8(3): 253-261.

60.Antoniades C, Antonopoulos AS, Bendall JK, Channon KM (2009) Targeting redox signaling in the vascular wall: from basic science to clinical practice. Curr Pharm Des 15(3):329-342.

61. Boden G, Song WW (2008) Effects of insulin and free fatty acids on matrix metalloproteinases. Current Diabetes Reports 8(3): 239-242.

62. Balkau B, Deanfield JE, Després JP, Bassand JP, Fox KA, et al.(2007) International Day for the Evaluation of Abdominal Obesity (IDEA): a study of waist circumference, cardiovascular disease, and diabetes mellitus in 168,000 primary care patients in 63 countries. Circulation 116(17): 1942-1951.

63. Welch V, Tang SS (2007) Treatment and control of BP and lipids in patients with hypertension and additional risk factors. Am J Cardiovasc Drugs 7(5): 381-399.

64. Qaseem A, Vijan S, Snow V, Cross JT, Weiss KB, et al. (2007) Glycemic control and type 2 diabetes mellitus: the optimal hemoglobin A1c targets. A guidance statement from the American College of Physicians. Ann Intern Med 147(6): 417-422.

65. Cornier MA, Marshall JA, Hill JO, Maahs DM, Eckel RH (2011) Prevention of overweight/obesity as a strategy to optimize cardiovascular health. Circulation 124(7): 840-850. 